\title{
The Back Home Trial
}

\section{General Practitioner-Supported Leaflets May Change Back Pain Behavior}

\author{
Lisa Roberts, PhD, MCSP, ${ }^{*} \dagger$ Paul Little, FRCGP,$\ddagger$ Judith Chapman, MSc, MCSP, $†$ \\ Ted Cantrell, FRCP, $\mathbb{S}$ Ruth Pickering, PhD,\| and John Langridge, MSc, FCSP*
}

Study Design. A single-blind randomized controlled trial of a leaflet developed for people with acute low back pain was compared with the usual general practitioner management of back pain.

Objective. To test the effectiveness of a patient information leaflet on knowledge, attitude, behavior, and function.

Summary of Background Data. Despite the commonality of back pain in general practice, little evidence on the effectiveness of simple interventions such as leaflets and advice on self-management has been reported. On the basis of a five-stage needs analysis, a simple leaflet was developed that considered the views of patients and health professionals.

Methods. For this study, 64 patients with acute back pain were assigned to the leaflet or control group. The participants were visited at home after 2 days, 2 weeks, then 3,6 , and 12 months, where they completed a range of self-report measures. Behavioral aspects were discreetly recorded by a "blinded" researcher. Primary outcomes were knowledge, attitude, behavior, and function.

Results. In all, 272 home visits were undertaken. The findings show that at 2 weeks, knowledge about sitting posture was greater in the leaflet group $(P=0.006)$, which transferred to a behavioral difference (sitting with lumbar lordosis support) when participants were unaware that they were being observed $(P=0.009)$. This difference remained significant at 3 months. Patients in the leaflet group also were better at maintaining a wide base of support when lifting a light object than the control subjects throughout all five assessments. There were no significant differences in the functional outcomes tested.

Conclusions. This trial demonstrates that written advice for patients can be a contributory factor in the initial general practitioner consultation because it may change aspects of knowledge and behavior. This has implications

From the "Department of Physiotherapy, Southampton University Hospitals Trust, the $†$ School of Health Professions and Rehabilitation Sciences, University of Southampton, $\ddagger$ Primary Medical Care, Faculty of Medicine, Health and Biological Sciences, University of Southampton, the $\mathbb{}$ Department of Rheumatology and Rehabilitation, Southampton University Hospitals Trust, and the \|Medical Statistics Group, University of Southampton, Highfield, Southampton, Hants, United Kingdom.

Funded by a Wessex Regional Health Authority research and development grant.

Acknowledgment date: July 18, 2001.

First revision date: September 28, 2001.

Acceptance date: March 4, 2002.

Device status/drug statement: The submitted manuscript does not contain information about medical devices or drugs.

Conflict of interest: An NHS research and development grant was received to support this work. No benefits in any form have been or will be received from a commercial party related directly or indirectly to the subject of this manuscript.

DOI: 10.1097/01.BRS.0000025724.24992.A9 for the management of acute back pain, with potential health gain. [Key words: advice, back pain, leaflet, primary care, randomized controlled trial] Spine 2002;27: 1821-1828

Back pain, commonly seen in general practice, is costly to the individual, health care providers, and society as a whole. The search continues for strategies to lessen this financial burden, but at this writing, little evidence has been reported on the effectiveness of simple, self-help interventions such as information leaflets.

Cherkin et $\mathrm{al}^{7}$ argued that "because back pain is typically a recurrent problem that improves with time regardless of treatment, effectively teaching patients to take more responsibility for their own care remains a high priority." Nordin claimed that when patients with nonspecific low back pain are given information, they are more satisfied at the first visit and require less health care. ${ }^{23}$ Therefore, it is evident that information and advice given by health professionals to patients may be a potent element of the health care intervention. ${ }^{3}$

In an accident and emergency setting, Jones et $\mathrm{al}^{14}$ reported that an educational intervention supplemented by a telephone call increased compliance in patients with low back pain who were in need of follow-up care. Indeed, all primary health care professionals, particularly general practitioners (GPs), are well placed to exert considerable influence on whether patients feel able to take an active role in their own health care, an empowering process.

The most obvious reason why individuals visit their GP is because they believe they have a health problem. ${ }^{11}$ As Cameron et $\mathrm{al}^{5}$ stated: "The opportunity to disclose one's concerns, to receive reassurances that one's symptoms are benign, and to receive treatments makes seeking medical care a comforting choice." In relation to low back pain, Bush et $\mathrm{al}^{4}$ reported that patients consulted their physician to obtain information and reassurance. How then can health professionals maximize their role in providing this information and reassurance?

One possibility involves using leaflets, which can act as a reminder after a medical consultation because, according to Livesley and Rider, ${ }^{16}$ "much that is said is forgotten." Other proposed benefits of leaflets include alleviation of anxiety, ${ }^{18}$ promotion of psychological benefit, ${ }^{18}$ and reduction of medicolegal problems that occur with dissatisfied patients. ${ }^{16}$ A leaflet allows people to absorb the content at a time and place appropriate to 
themselves, and can be used to provide an opportunity for people to identify their health beliefs.

Such advantages are not universally reported. Hazard et $\mathrm{al}^{10}$ reported no effect at 3 or 6 months in terms of pain, health status, and health care use in people reporting back pain when an educational pamphlet was mailed in an occupational setting. It also is important that leaflets are not seen as a substitute for good communication between the physician and the patient. ${ }^{9}$ As Hadler $^{8}$ said, "Does not everyone in pain deserve the empathy and human contact that can never occur in any educational booklet?"

Not only the content and presentation of leaflets are important, but also the manner in which the leaflet is issued. Harland et $\mathrm{al}^{9}$ argued that because doctors are viewed by patients as the primary source for information, leaflets may be best delivered by the doctors themselves during the consultation to achieve the most impact. Verbal reinforcement also may be essential. ${ }^{16}$

Regarding back pain, there have been several studies of educational interventions. Roland and Dixon ${ }^{25}$ reported that patients who received an information booklet (in a controlled trial) saw their GP on fewer occasions in the ensuing year than the control group that did not receive the booklet. Knowledge scores also were higher in the booklet group, but no differences were reported between the two groups in terms of absence from work. Unfortunately, the outcome measures did not include symptomatology or back protection behaviors, and allocation (based on date of birth) was not concealed.

Burton et $\mathrm{al}^{3}$ showed, in a double-blind randomized controlled trial, that carefully selected and presented information and advice about back pain can have a positive effect on patients' beliefs, particularly "fearavoidance beliefs about physical activity and beliefs about the inevitable consequences of back trouble." Patients who received the "novel patient educational booklet" also demonstrated a trend toward improved function.

More recently, Little et $\mathrm{al}^{15}$ reported that doctors can increase patients' satisfaction and moderately improve functional outcomes in the period immediately after the consultation, when back pain is worst, by using simple interventions such as endorsing a self-management booklet or giving advice to take exercise. However, although this study reported improvements in satisfaction, knowledge and pain/function, there is little information as to how this might have happened and whether the behavior of patients was altered.

Changing behavior is more difficult than changing beliefs or improving information levels. Arthur ${ }^{1}$ cites two studies reporting behavioral changes and increased knowledge levels. One study evaluated a GP practice leaflet, and the other an osteoporosis education program. What remains unproved is whether educational leaflets can change behavior in people with back pain. We describe the process of developing a new educational leaflet and report the primary outcomes from a randomized
Table 1. Leaflet Development Stage 2: Results of the Total Scores From 13 Interviews

Stage 2

Total Score*

\begin{tabular}{ll}
\hline How to lift things & 33 \\
What treatment is available & 33 \\
Where to get help/further advice & 33 \\
Getting back to work & 31 \\
What exercises to do & 30 \\
How to position myself (e.g., lying, sitting) & 29 \\
What can I do to get/keep myself fit & 29 \\
How soon is my back pain likely to settle & 28 \\
How to sleep or rest comfortably & 27 \\
How to control pain using self-help measures (e.g., hot & 27 \\
water bottles) & \\
How the back works & 26 \\
How to modify my life to prevent my back pain from & 25 \\
coming back & 24 \\
How to drive & 24 \\
What are some causes of low back pain & 23 \\
How to modify my bedding and pillows to help my pain & 22 \\
What makes up the spine & 21 \\
How to get washed or dressed easily & 21 \\
How to control my pain by using tablets & 21 \\
Getting back to social and leisure activities & 21 \\
Getting back to physical relationships & 17 \\
How to get about & 17 \\
How to do my daily tasks & 17 \\
How to cough and sneeze & 16 \\
How to manage the shopping & 16 \\
Getting back to sports & 16 \\
Getting back to gardening & 15 \\
Getting back to DIY &
\end{tabular}

* 5-point Likert scale: 3 (essential), 2 (very important), 1 (important), 0 (not very important or not relevant). The maximum score attainable is 39 . DIY = "Do it yourself."

controlled trial that evaluated the effectiveness of this leaflet on knowledge, attitude, behavior, and function in people with acute low back pain.

\section{Methods}

Development of the Back Home Leaflet. A needs analysis of patients who had recently experienced acute low back pain was undertaken to determine the content of the leaflet.

Stage 1. A brief questionnaire was given to patients $(\mathrm{n}=7)$ on their first visit to the GP with an episode of acute back pain, asking them to identify topics about which they would most like advice from their physician. The 27 topics identified are listed in Table 1.

Stage 2. Semistructured interviews were undertaken $(\mathrm{n}=$ 13), with people who experienced recent back pain attending an outpatient physiotherapy department. During the interview, the patients were asked to rate the 27 topics identified in Stage 1 , using a Likert scale. The preferences found were used to order the topics presented in Table 1. In the evaluation of the responses, the patients experiencing their first episode of back pain $(\mathrm{n}=5)$ were analyzed as a subgroup to ensure that their needs were specifically addressed.

Stage 3. The list of topics and the Likert scale from Stage 2 then were given to patients attending a back school $(\mathrm{n}=9)$ who had experienced back pain for several weeks, and thus could reflect over a longer time span. Interestingly, their responses were more passive than those from the patients in Stage 2. They 
considered "what treatment is available" as most important, whereas "how to control my pain using self-help measures" ranked only 22nd (compare with the order in Table 1).

Stage 4. Opinions were sought from senior chartered physiotherapists ( $\mathrm{n}=12$ ), who were keen to include details of simple anatomy to explain "what makes up the spine." The patients had ranked this sixth in Stage 2. Another area of controversy involved giving advice on specific back exercises. After much debate, the consensus was to omit details of exercises, because professionals were reluctant to recommend specific back exercises without first assessing patients. This conflicted with the patients" agenda. "What exercises to do" ranked fifth in Stage 2 and third for the subgroup experiencing acute back pain for the first time. Further opinions on the content of the leaflet were sought from a rheumatologist and a GP research fellow, who discussed the potential content with other GP colleagues.

Stage 5. The draft leaflet, termed Back Home, was produced and evaluated, using a questionnaire, by patients attending back schools $(\mathrm{n}=10)$.

With the agenda established from potential recipients of the leaflet and from the health professionals who might issue it, the evidence base for the content was reviewed. ${ }^{24}$ Much of the advice on positioning (including sitting) and manual handling was based on Nachemson's ${ }^{21,22}$ work on lumbar disc pressure measurements and basic biomechanics. Specific to sitting, the more the lumbar spine was moved toward lordosis, the less disc pressure Nachemson detected. ${ }^{21}$ The aim of using a lumbar roll, for example, is to help maintain this lordosis. In addition to ergonomic advice aimed at encouraging personal control and decreasing levels of pain, the rationale for using ice and heat, specifically for pain relief, has been described. ${ }^{13,17}$

The final Back Home leaflet comprises 12 DL-size $(21 \times 10$ $\mathrm{cm})$ pages of green monotone print on ivory paper. The cover contains the positive messages "you can ease your pain" and "most people do get better within 4 weeks." There are interactive aspects, encouraging patients to list the movements or positions that increase their pain. Patients are asked to identify positions in which they are most comfortable, with suggestions including crook lying, sitting in a straight chair and using a pad to support the lumbar spine, or lying supine with the legs supported, for example, on a chair or sofa.

The leaflet also includes simple anatomy, advice on the limited use of radiographs, simple messages about mattresses, and information on analgesia, the need to minimize bed rest, and the importance of keeping mobile. There are practical tips for getting in and out of bed, standing, sitting, getting washed and dressed, driving, bracing for coughing and sneezing, and lifting. In addition, there is instruction in self-help measures such as applying ice or heat and advice about general exercise, encouraging activities such as walking, swimming, yoga, and relaxation. Sources of further reading and helpful addresses are included on the back cover. Gunning's Fog Index, describing the readability of the leaflet rates the reading level at 6.5 , within the range recommended for health education leaflets (Grades 5-9). ${ }^{6}$

Trial of the Leaflet. A single-blind, randomized controlled trial was undertaken in southern England to evaluate the leaflet. The area included the city of Southampton and adjacent, largely rural, New Forest. Ethical approval was granted from the Southampton and South West Hants Health Authority Ethics Committee.

All the GPs in New Forest and west of Southampton were contacted, and 51 consented to participate from 26 practices. The participating practices were randomly allocated to either the control or experimental group within pairs of practices matched for location (to control for socioeconomic area) and number of participating GPs in the practice (range, 1-9). Randomization, used in each pair, was accomplished with computer-generated random numbers. The allocation was concealed from the researcher until the completion of data collection.

The participants were experiencing acute back pain, defined as pain in an area bounded by the 12th thoracic vertebra and 12th ribs superiorly, the gluteal folds inferiorly, and the contours of the trunk laterally. The inclusion criteria for the trial required written consent, an age of 16 to 60 years (to exclude children and minimize the risk of symptoms secondary to osteoporosis), no low back pain in the previous 6 months (to identify the current symptoms as a new episode), back pain severe enough to warrant at least 3 days off work or an equivalent (to exclude people with mild symptoms), and ability to read and understand English. The trial excluded people who presented with any "red flag" signs or symptoms, had received previous formal instruction in back pain management (because they could have been influenced by this education), sought treatment from private practitioners such as physiotherapists, chiropractors, or osteopaths before the second assessment (at 2 weeks), were pregnant or postpartum, or were involved in litigation.

Intervention. The GPs in the control group continued with their usual management and advice for patients with acute back pain. The GPs in the experimental group also gave the patient a copy of the Back Home leaflet, verbally reinforcing the content by making the following standardized empowering statement to reflect clinical practice and maximize any potential benefit of the leaflet: "This leaflet, called Back Home, gives you practical hints about how you can help to ease your back pain. Please read the leaflet carefully and use as many of the ideas as you can. This leaflet is important. It will allow you to be in control of your back pain." There were two boxes for the GPs to tick, indicating whether they had read the statement to the patient or not.

Once the patient had consented to enter the trial, the GP telephoned an answer phone to record the person's name and contact details, ensuring that the first assessment could occur within 2 working days of the GP consultation. Throughout the trial, a telephone advice line was available for any GPs in the experimental group to use if patients asked any questions arising from information in the leaflet that the GP did not feel able to answer. This service was never used.

Outcome Measures. The participants were followed up at home on five occasions: within 2 working days, then after 2 weeks, 3 months, 6 months, and 1 year. Assessment comprised a battery of self-report questionnaires (Table 2). The same researcher carried out all the data collection. The primary outcomes of the trial were knowledge, attitude, observable behavior, and function. Preexisting questionnaires were used wherever possible, and the order in which the outcome measures were administered was randomized. Pilot work had previously been undertaken with 20 patients to test the practicality of the outcome measures, especially those that had been developed or revised. ${ }^{24}$ 
Table 2. Outcome Measures Used in the Back Home Trial

\begin{tabular}{|c|c|c|c|c|c|}
\hline & \multicolumn{5}{|c|}{ Assessment } \\
\hline & $\begin{array}{c}1 \\
2 \text { Days }\end{array}$ & $22^{2}$ & $\begin{array}{c}3 \\
3 \text { Months }\end{array}$ & $\begin{array}{c}4 \\
6 \text { Months }\end{array}$ & $\begin{array}{c}5 \\
12 \text { Months }\end{array}$ \\
\hline \multicolumn{6}{|l|}{ Self-report } \\
\hline Anxiety ${ }^{19}$ & $\boldsymbol{}$ & $\boldsymbol{}$ & $\boldsymbol{}$ & レ & レ \\
\hline Demographic details* & $\nu$ & - & - & - & - \\
\hline Attitude ${ }^{*}$ & - & レ & - & - & - \\
\hline Back-to-work data* & - & $\nu$ & $\boldsymbol{}$ & レ & $\boldsymbol{}$ \\
\hline Function $^{27}$ & $\boldsymbol{\nu}$ & $\nu$ & レ & レ & レ \\
\hline Knowledge ${ }^{\text {after } 12}$ & - & $\nu$ & - & - & - \\
\hline Management/treatment* & - & $\nu$ & $\boldsymbol{\nu}$ & $\boldsymbol{}$ & レ \\
\hline Multidimensional health locus of control $(A)^{29} \&(C)^{30}$ & $\boldsymbol{}$ & $\nu$ & $\nu$ & $\boldsymbol{V}$ & レ \\
\hline Pain $\mathrm{I}^{\text {ffter } 20}$ & $\nu$ & - & - & - & - \\
\hline Pain II after 20 & - & $\boldsymbol{}$ & $\boldsymbol{\nu}$ & $\boldsymbol{}$ & レ \\
\hline Perceived control ${ }^{\text {after } 2}$ & $\boldsymbol{}$ & $\nu$ & $\nu$ & 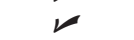 & 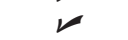 \\
\hline Satisfaction ${ }^{*}$ & $\nu$ & - & - & - & - \\
\hline Satisfaction $\|^{*}$ & - & $\boldsymbol{V}$ & $\boldsymbol{V}$ & $\boldsymbol{V}$ & $\boldsymbol{V}$ \\
\hline Pain diary ${ }^{\text {after } 20}$ & \multicolumn{2}{|c|}{$\begin{array}{l}\text { Completed between } \\
\text { assessments } 1 \& 2\end{array}$} & - & - & - \\
\hline \multicolumn{6}{|l|}{ By researcher } \\
\hline Home assessment I* & $\boldsymbol{\nu}$ & - & - & - & - \\
\hline Home assessment II* & - & レ & - & - & - \\
\hline Observable behavior* & $\boldsymbol{\nu}$ & 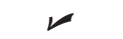 & $\boldsymbol{\nu}$ & $\boldsymbol{V}$ & $\boldsymbol{}$ \\
\hline
\end{tabular}

* Denotes the questionnaires developed by the research team because appropriate questionnaires were not available. after $=$ based on

Knowledge. The knowledge outcome measure was based on the earlier Back Quiz ${ }^{12}$ and revised to reflect specific information provided in the Back Home leaflet. This measure contained nine multiple-choice questions, each with a choice of five possible answers plus a category for “don't know." Knowledge could be assessed only once in this trial, because if it had been measured as a baseline variable, it might have influenced the participants in acquiring additional information, thus contaminating any impact of the leaflet.

Attitude. Six questions were included about patients' attitudes toward their back pain. One of these questions ("Do you think you can manage your back pain on your own?"), with three answer choices, "yes," "no," and "don't know," was selected in advance as a primary outcome and analyzed as “yes” versus “no"/“don't know.”

Observable Behavior. The observable behavior outcome involved simple, dichotomous observations of the patient undertaking four activities and recording "yes," "no," or "did not undertake the activity." The observations were as follows:

If they were in bed, did they get up through side-lying?

If they were sitting, did they make any attempt to support their lumbar lordosis (with a pillow or cushion).

How did they get up from the sitting position? Did they make any attempt to move to the front of the chair first?

In lifting or picking a light object up from the floor, (a) did they attempt to bend their knees, and (b) did they have a suitably wide base of support, defined as having their feet greater than or equal to the distance of their shoulders?

These activities had been highly rated in the needs analysis for development of the leaflet because they were functional and could be readily and discreetly observed. Pilot work was undertaken with this outcome. ${ }^{24}$ Only one person actually was in bed for the second assessment, so the first activity was omitted from the analysis.

Function. Function was assessed using the Aberdeen Low Back Pain Scale, ${ }^{27}$ a 19 -item scale designed for use in the community. The scale contains questions on pain distribution and function, with 3 to 6 possible answers. It was anticipated that this scale would be more sensitive in detecting smaller changes than dichotomous scales such as the Roland Morris Disability Questionnaire. ${ }^{26}$

Statistical Analysis. In this trial, knowledge and attitude were measured only at 2 weeks, whereas behavior and function were assessed at five points during the year-long monitoring of patients. All knowledge, attitude, and behavior observations were treated as binary items, with "don't know" and "not applicable" responses excluded. Odds ratios, associated 95\% confidence intervals, and Pearson $\chi^{2}$ statistics are presented where numbers allowed. Otherwise, exact tests based on a patient level analysis are reported. In part, because of uneven recruitment, with a few GPs recruiting most of the participants and many recruiting none, there were differences between the groups at baseline regarding the highest level of education achieved and whether the occupation of the participants involved manual work, whether previous episodes of back pain had occurred, and whether the participant engaged in regular exercise before the current episode of back pain (Table 3). With the exception of the highest level of education achieved, it might be anticipated that these differences would favor the control group.

We also compared the binary outcomes achieving significance in unadjusted comparisons in logistic regression models, and controlled for these factors. Accounting for baseline differences generally increased the significance of results. However, estimated odds ratios became extremely large, suggesting that 
Table 3. Baseline Characteristics in the Trial of Information Leaflets for Back Pain

\begin{tabular}{|c|c|c|}
\hline Variable & $\begin{array}{l}\text { Leaflet } \\
(\mathrm{n}=35) \\
\mathrm{n}(\%)\end{array}$ & $\begin{array}{c}\text { Control } \\
(\mathrm{n}=28) \\
\mathrm{n}(\%)\end{array}$ \\
\hline Mean age (years) & $39.2 \pm 10.9$ & $39.3 \pm 9.7$ \\
\hline Min-max & $16-58$ & $22-56$ \\
\hline \multicolumn{3}{|l|}{ Gender } \\
\hline Female & $13(37)$ & $9(32)$ \\
\hline Male & $22(63)$ & $19(68)$ \\
\hline \multicolumn{3}{|l|}{ Social class* } \\
\hline I & 0 & $3 / 27(11)$ \\
\hline II & $3(9)$ & $4 / 27(15)$ \\
\hline III & $12(34)$ & $13 / 27(48)$ \\
\hline IV & $16(46)$ & $4 / 27(15)$ \\
\hline V & $4(11)$ & $2 / 27(7)$ \\
\hline Unclassifiable & 0 & $1 / 27(4)$ \\
\hline Manual* & $24(69)$ & $11 / 27(41)$ \\
\hline Previous back pain & 31 (89) & $16(57)$ \\
\hline $\begin{array}{l}\text { Those with previous back pain who } \\
\text { consulted their GP }\end{array}$ & $27 / 31(87)$ & $11 / 16(69)$ \\
\hline $\begin{array}{l}\text { Low educational achievement (0-level/ } \\
\text { CSE/GCSE or lower) }\end{array}$ & $32(92)$ & $15(54)$ \\
\hline In paid employment & $28(80)$ & $24(86)$ \\
\hline \multicolumn{3}{|l|}{ Smoking } \\
\hline Never & $6(17)$ & $9(32)$ \\
\hline Yes & $22(63)$ & $13(46)$ \\
\hline Used to & $7(20)$ & $6(21)$ \\
\hline $\begin{array}{l}\text { Involved in regular sports or active } \\
\text { hobbies }\end{array}$ & $8(23)$ & $12(43)$ \\
\hline
\end{tabular}

* One participant with missing values in the control group.

CSE $=$ Certificate of secondary education; GCSE $=$ General certificate of secondary education.

the numbers available were insufficient to fit models reliably. For this reason, and because baseline difference tended to favor the control group, controlled results are not generally reported. In two cases, the estimated odds ratios were reduced, and the association no longer achieved significance. For these cases only, controlled results are reported.

We also undertook logistic regression, including clustering at the practice level in Stata, for the binary outcomes achieving significance in unadjusted standard logistic regression. The confidence intervals (CI) around estimated odds ratios usually were more narrow, indicating a lack of intrapractice correlation for the outcomes in question. Again, the results are reported only for the one outcome in which the confidence inter- val became wider and significance was lost. Functional scores were compared between groups using Mann-Whitney $U$ tests, and leaflet-control differences in the mean score were presented with $95 \%$ confidence intervals.

\section{Results}

The 64 people who entered the trial were randomized over a 21/2-year period, and 272 home visits were undertaken. One patient left the trial for personal reasons before the second assessment. The median number of days (and 90th percentile) between the first assessment and those scheduled to take place after 2 weeks, then after 3 , 6, and 12 months were in fact 14 (16), 86 (95), 183 (200), and 373 (391), respectively.

The demographic details describing the 64 patients are shown in Table 3 . The results of the primary analyses are shown in Tables 4 to 6 .

\section{Knowledge}

At 2 weeks, two of the nine knowledge questions were significant at the $5 \%$ level, as shown in Table 4 . These questions specifically related to sitting posture and identifying the easiest position for putting on socks or tights. After accounting for baseline differences, the odds ratio associated with the "easiest position to put on socks/ tights" was increased to 5.13 (95\% CI, 0.91-28.75) with a higher $P$ value $(P=0.043)$.

\section{Attitude}

At 2 weeks, when patients were asked "Do you think you can manage your back pain on your own?" there was no significant difference between the leaflet and control groups.

\section{Observable Behavior}

The results from observing behaviors are shown in Table 5. It can be seen that sitting with the lumbar lordosis supported was statistically significant at the $5 \%$ level at 2 days, 2 weeks, and 3 months, as was maintaining a wide base of support during lifting, which remained significant throughout all the assessments. Controlling for baseline differences resulted in a reduction of the odds

Table 4. Patients Reporting Correct Answers in the Knowledge Outcome Measure at 2 Weeks and Responding "Yes" to the Attitude Question

\begin{tabular}{|c|c|c|c|c|c|}
\hline & $\begin{array}{c}\text { Leaflet } \\
\text { n }(\%)\end{array}$ & $\begin{array}{c}\text { Control } \\
\mathrm{n}(\%)\end{array}$ & $\begin{array}{l}\text { Leaflet } \\
\text { Control }\end{array}$ & OR $(95 \% \mathrm{Cl})$ & $P$ \\
\hline Most common cause of back pain & $9 / 32(28)$ & $4 / 26(15)$ & 2.15 & $(0.58-8.02)$ & $0.247^{*}$ \\
\hline Least stressful position & $11 / 32(34)$ & $11 / 26(42)$ & 0.71 & $(0.25-2.08)$ & $0.536^{*}$ \\
\hline Most likely to worsen pain & $18 / 31(58)$ & $15 / 26(58)$ & 1.02 & $(0.35-2.92)$ & $0.977^{*}$ \\
\hline Easiest position for putting on socks/tights & $13 / 32(41)$ & $4 / 26(15)$ & 3.76 & $(1.05-13.50)$ & $0.036^{*}$ \\
\hline Application time for ice pack & 4/32 (13) & $1 / 26(4)$ & 3.57 & $(0.37-34.11)$ & $0.367 \dagger$ \\
\hline Frequency of position changing & $14 / 32(44)$ & $9 / 26(35)$ & 1.47 & $(0.51-4.27)$ & $0.479 *$ \\
\hline Tissue affected by heat pack & $20 / 32(63)$ & $19 / 26(73)$ & 0.61 & $(0.20-1.89)$ & $0.393^{*}$ \\
\hline Best sitting position & $19 / 32(59)$ & $6 / 26(23)$ & 4.87 & $(1.54-15.44)$ & $0.006^{*}$ \\
\hline Best form of exercise & $31 / 32(97)$ & $22 / 26(85)$ & 5.64 & $(0.59-53.93)$ & $0.163 \dagger$ \\
\hline Do you think you can manage your back pain on your own? & $15 / 32(47)$ & $14 / 26(54)$ & 0.76 & $(0.27-2.14)$ & $0.597^{*}$ \\
\hline
\end{tabular}


Table 5. Observed Behavior at Each Follow-up Visit

\begin{tabular}{|c|c|c|c|c|c|c|}
\hline Observation & Follow-up & $\begin{array}{l}\text { Leaflet } \\
\text { n (\%) }\end{array}$ & $\begin{array}{l}\text { Control } \\
\mathrm{n}(\%)\end{array}$ & $\begin{array}{l}\text { Leaflet } \\
\text { Control }\end{array}$ & OR $(95 \% \mathrm{Cl})$ & $P$ \\
\hline \multirow[t]{5}{*}{ Did they attempt to support the lumbar lordosis? } & 2 Days & $14 / 31(45)$ & $4 / 27(15)$ & 4.74 & $(1.32-16.96)$ & $0.013^{*}$ \\
\hline & 2 Weeks & $13 / 30(43)$ & $3 / 26(12)$ & 5.86 & $(1.44-23.85)$ & $0.009^{*}$ \\
\hline & 3 Months & $12 / 30$ (40) & $3 / 25(12)$ & 4.89 & (1.19-20.03) & $0.020^{*}$ \\
\hline & 6 Months & $6 / 25(24)$ & $5 / 22(23)$ & 1.07 & $(0.28-4.16)$ & $0.918^{*}$ \\
\hline & 1 Year & 10/25 (40) & $4 / 20(20)$ & 2.67 & $(0.69-10.36)$ & $0.150^{*}$ \\
\hline \multirow[t]{5}{*}{ Did they move to the front of the chair first? } & 2 Days & 29/32 (91) & $21 / 28$ (75) & 3.22 & $(0.75-13.94)$ & $0.105 \dagger$ \\
\hline & 2 Weeks & 27/30 (90) & $21 / 26(81)$ & 2.14 & $(0.46-10.00)$ & $0.451 \dagger$ \\
\hline & 3 Months & 28/29 (97) & $22 / 24$ (92) & 2.55 & $(0.22-29.93)$ & $0.584 \dagger$ \\
\hline & 6 Months & 23/24 (96) & 20/22 (91) & 2.30 & $(0.19-27.30)$ & $0.600 \dagger$ \\
\hline & 1 Year & $23 / 24(96)$ & $19 / 21(91)$ & 2.42 & $(0.20-28.80)$ & $0.592 \dagger$ \\
\hline \multirow[t]{5}{*}{ Did they attempt to bend their knees? } & 2 Days & $19 / 20(95)$ & $14 / 15(93)$ & 1.36 & $(0.08-23.62)$ & $1.000 \dagger$ \\
\hline & 2 Weeks & $30 / 30(100)$ & $23 / 25$ (92) & - & - & $0.202 \dagger$ \\
\hline & 3 Months & $30 / 30(100)$ & $23 / 25$ (92) & - & - & $0.202 \dagger$ \\
\hline & 6 Months & $25 / 26(96)$ & $21 / 22(96)$ & 1.19 & $(0.07-20.21)$ & $1.000 \dagger$ \\
\hline & 1 Year & 22/23 (96) & 20/21 (95) & 1.10 & $(0.06-18.77)$ & $1.000 \dagger$ \\
\hline \multirow{5}{*}{ Did they have a suitably wide base? } & 2 Days & 18/20 (90) & $3 / 15(20)$ & 36.0 & $(5.21-248.66)$ & $0.000^{*}$ \\
\hline & 2 Weeks & 22/30 (73) & $3 / 25$ (12) & 20.17 & $(4.72-86.19)$ & $0.000^{*}$ \\
\hline & 3 Months & $21 / 29(72)$ & $7 / 25$ (28) & 6.75 & $(2.05-22.27)$ & $0.001^{*}$ \\
\hline & 6 Months & 19/26 (73) & $9 / 22(41)$ & 3.92 & $(1.17-13.20)$ & $0.024^{*}$ \\
\hline & 1 Year & $16 / 23(70)$ & $7 / 21$ (33) & 4.57 & $(1.28-16.27)$ & $0.016^{*}$ \\
\hline
\end{tabular}

* Asymptotic $\chi^{2}$ test

+ Exact $\chi^{2}$ test.

$\mathrm{OR}=$ odds ratio (not calculated when rates are $0 \%$ or $100 \%$ ); $\mathrm{Cl}$, confidence interval.

ratio for "Did they support the lumbar lordosis?" at 3 months to 3.41 (95\% CI, 0.67-17.38), with $P$ value of 0.119 . Taking account of clustering at the GP practice level increased the confidence interval associated with the odds ratio for "Did they have a suitably wide base of support?" at 1 year to $0.97-21.45$.

\section{Function}

There were no statistically significant differences in the Aberdeen Low Back Pain Scale between the control and leaflet groups in their functional outcome.

\section{Discussion}

In developing the content of the Back Home leaflet, it was apparent that the priorities of patients and health

Table 6. Percentage Functional Scores

\begin{tabular}{|c|c|c|c|c|}
\hline & Leaflet* & Control* & $\begin{array}{l}\text { Leaflet-control mean } \\
\text { difference }(95 \% \mathrm{CI})\end{array}$ & $P \dagger$ \\
\hline 2 Working days & $\begin{array}{c}42.7 \pm 11.9 \\
18.1-69.6 \\
(\mathrm{n}=35)\end{array}$ & $\begin{array}{c}42.6 \pm 13.6 \\
16.7-77.8 \\
(n=28)\end{array}$ & $0.1(-6.5-6.3)$ & 0.678 \\
\hline 2 Weeks & $\begin{array}{c}37.7 \pm 14.8 \\
15.9-73.9 \\
(n=32)\end{array}$ & $\begin{array}{c}35.6 \pm 15.9 \\
5.6-73.6 \\
(n=26)\end{array}$ & $2.0(-6.1-10.1)$ & 0.766 \\
\hline 3 Months & $\begin{array}{c}14.6 \pm 17.6 \\
0.0-62.3 \\
(n=32)\end{array}$ & $\begin{array}{c}14.4 \pm 17.6 \\
0.0-56.9 \\
(n=25)\end{array}$ & $0.2(-9.2-9.6)$ & 0.878 \\
\hline 6 Months & $\begin{array}{c}14.7 \pm 16.1 \\
0.0-69.6 \\
(\mathrm{n}=26)\end{array}$ & $\begin{array}{c}8.6 \pm 10.1 \\
0.0-33.3 \\
(n=23)\end{array}$ & $6.1(-1.8-13.9)$ & 0.180 \\
\hline 1 Year & $\begin{array}{c}11.0 \pm 14.2 \\
0.0-60.9 \\
(\mathrm{n}=25)\end{array}$ & $\begin{array}{l}8.1 \pm 9.6 \\
0.0-30.6 \\
(n=23)\end{array}$ & $2.9(-4.2-10.0)$ & 0.363 \\
\hline
\end{tabular}

* Figures are mean \pm standard deviation, min-max.

† Mann Whitney $U$ test.

$\mathrm{Cl}$, confidence interval. professionals differed, especially about exercises and spinal anatomy. Therefore, in developing any educational materials, it is paramount to canvass the views of potential users, in this case, people with acute low back pain. We suggest that it is particularly important to ascertain the needs of the subgroup of people experiencing their first episode of back pain to ensure that their needs are addressed.

A total of 35 primary outcomes were specified in advance: 9 assessing knowledge, 1 assessing attitude, 20 assessing behavior, and 5 assessing function. This number of comparisons would be expected to result in two significant findings at the $5 \%$ level through chance alone. In fact, 10 comparisons were significant in unadjusted analyses, five at the $1 \%$ level, suggesting real differences between the patients who received the leaflet and those who did not. Eight comparisons remain significant after control was used for baseline differences or clustering at the GP practice level.

We demonstrated differences in specific areas of knowledge, which then were reflected in a change of behavior. Care was taken to ensure that patients were unaware that their behavior was being observed. It must be remembered that these results were achieved with a very simple intervention, given at the initial GP consultation, with minimal resource or training implications.

The patients in this trial were monitored from within 2 days of their initial GP consultation until 12 months afterward. The leaflet was given at the first appointment when patients were still experiencing considerable pain and distress. Since it is possible that at this point their cognition could have been impaired, because of pain and medication, the leaflet was designed to be very basic, giving only simple, practical advice. In the current trial it was is- 
sued with verbal reinforcement by the GP, as recommended by Livesley and Rider ${ }^{16}$ to maximize its impact. This process also mirrors clinical practice, in which educational materials probably are given with reinforcement.

The major strength of this intervention was its simplicity. This elementary, practical leaflet was designed to be used in primary care. It focuses on managing acute low back pain and is cheap to produce. It does not require complex training by the health professional issuing it, but merely active support and reinforcement. Despite its simplicity, it brought about changes in knowledge and behavior in people with acute low back pain.

Interestingly, the observed use of lumbar supports such as a pillow or cushion during sitting remained statistically significant for the first 3 months. However, at 6 months, this difference was no longer evident, suggesting that patients used this strategy during the acute phase of their back pain episode. They may not continue this behavior as a prophylactic measure over the long term.

Secondary outcomes measured in this trial also have shown the Back Home leaflet to be associated with clinically important differences in perceptions of control, anxiety, and satisfaction. ${ }^{24}$ Patients who received the leaflet perceived themselves as more able to control their low back pain than those in the control group. In addition, they reported lower levels of anxiety and higher levels of satisfaction with the information they received and the way their back pain was being managed. ${ }^{24}$

Some problems were encountered in the trial. The recruitment of patients by GPs ( 64 patients from 51 GPs in $2 \frac{1}{2}$ years) was slower and more uneven than we had planned, and this may account for the imbalance in the baseline characteristics. Additional work with participating GPs showed that "pressure of work" and "difficulties remembering to enter patients" as the main reasons for the poor recruitment. ${ }^{24}$ Randomization occurred at the level of the GP practice, so the allocation could not be concealed when GPs recruited patients into the trial. Although this had certain advantages, in that GPs could verbally reinforce the leaflet (using a standardized empowering statement), and in that it probably reduced contamination from patients possibly seeing different GPs within the same practice throughout the duration of the trial or talking to other patients who had been given a leaflet, it may have been responsible for the poor recruitment in control practices, with two GPs in this group withdrawing because the trial "did not provide any help to the patients at the time when they needed help." For practical reasons, randomizing at the patient level may be a better option in this type of trial.

The demographic details outlined in Table 3 show that the social class of the leaflet group was lower than that of the control group, and that there were more manual workers in the leaflet group. These differences may have reduced any potential impact gained from the leaflet, with the result that the current findings, if anything, underestimated the true benefit. The other main difference between the groups was the greater number of pa-
The Back Home Trial

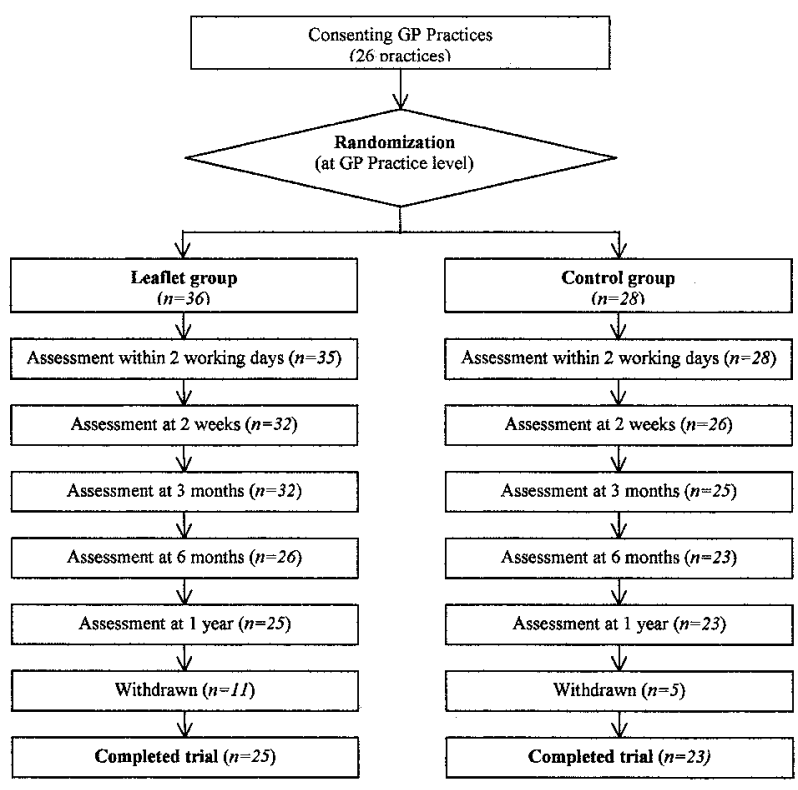

Figure 1. The Back Home trial.

tients in the leaflet group who had experienced previous episodes of low back pain. This may have affected patients' previous knowledge, such that they had learned how to manage their pain from previous experience. Attempts were made to minimize this problem by excluding patients who had received formal instruction in back care as well as patients who had experienced low back pain within the previous 6 months. The baseline differences were addressed in the analysis, and the most conservative results are presented.

The leaflet did not affect function as measured by the Aberdeen Low Back Pain Scale. ${ }^{27}$ Perhaps the reason for this was that the function scores changed most between 2 weeks and 3 months and an intermediary measurement, at 6 weeks, for example, may have been more sensitive. Furthermore, the leaflet could perhaps have been more strongly relevant to the participants' individual lifestyles. One reported research finding is that education is more successful when people are taught how to incorporate learned health behavior into their daily routines. ${ }^{28}$ This could be achieved either by the health professional taking time to personalise the content at the initial consultation, which is unrealistic in the context of a GP surgery, or by increasing the interactive content of the leaflet. Further work is needed to determine the effect of personalising information in leaflets on a population with low back pain.

In conclusion, Burton et $\mathrm{al}^{3}$ have previously claimed that "information and advice may be a potent element of the health care intervention." The Back Home trial has shown that a simple leaflet may be a useful adjunct to management strategies that is particularly well suited to primary care. Although recruitment to the Back Home trial proved to be difficult, the results suggest that GP- 
supported leaflets may change aspects of behavior in people with acute low back pain.

\section{- Key Points}

- Leaflets given to patients with acute low back pain in an initial GP consultation may change aspects of behavior and knowledge.

- Simple leaflets may be a useful adjunct to management strategies for patients with acute low back pain.

- Patient information leaflets are well suited to primary care.

\section{References}

1. Arthur V. Written patient information: A review of the literature. J Adv Nurs 1995;21:1081-6.

2. Bradley C, Brewin CR, Gamsu DS, et al. Development of scales to measure perceived control of diabetes mellitus and diabetes-related health beliefs. Diabet Med 1984;1:213-18.

3. Burton AK, Waddell G, Tillotson KM, et al. Information and advice to patients with back pain can have a positive effect. Spine 1999;24:2484-91.

4. Bush T, Cherkin D, Barlow W. The impact of physician attitudes on patient satisfaction for low back pain. Arch Family Med 1993;2:301-5.

5. Cameron L, Leventhal EA, Leventhal H. Seeking medical care in response to symptoms and life stress. Psychosom Med 1995;57:37-47.

6. Chapman J, Langridge J. Physiotherapy health education literature. Physiotherapy 1997;83:406-12.

7. Cherkin DC, Deyo RA, Street JH, et al. Pitfalls of patient education: Limited success of a program for back pain in primary care. Spine 1996;21:345-55.

8. Hadler NM. Point of view. Spine 1996;21:355.

9. Harland CC, Madeley RJ, Millard LG. Information leaflets in the dermatology out-patient waiting area. Br J Dermatol 1992;127:492-6.

10. Hazard RG, Reid S, Haugh LD, et al. A controlled trial of an educational pamphlet to prevent disability after occupational low back injury. Spine 2000;25:1419-23.

11. Ingham JG, Miller P McC. Self-referral to primary care: Symptoms and social factors. J Psychosom Res 1986;30:49-56.

12. Jessep S. Comparison study of the effectiveness of two methods of back education: A pilot study. N Z J Physiother 1991;19:32-9.

13. Johnson L, Kitchen S. Heat and cold: Conduction methods. In: Kitchen S, Bazin S, eds. Clayton's Electrotherapy. 10th ed. London: WB Saunders, 1996:127-40

14. Jones SL, Jones PK, Katz J. Compliance for low back pain patients in the emergency department: A randomized trial. Spine 1988;13:553-6.
15. Little P, Roberts L, Blowers H, et al. Should we give detailed advice and information booklets to patients with back pain? A randomized controlled factorial trial of a self-management booklet and doctor advice to take exercise for back pain. Spine 2001;26(19)2065-72.

16. Livesley PJ, Rider MA. Joint replacement and patient education. Int Orthop 1993;17:34-6.

17. Low J, Reed A. Electrotherapy Explained. Principles and Practice. 2nd ed. Oxford: Butterworth Heinemann, 1994:179-205.

18. Luker K, Caress AL. Rethinking patient education. J Adv Nurs 1989;14: 711-18.

19. Marteau T, Bekker H. The 6-Item Short Form of the State Scale of the Spielberger State-Trait Anxiety Inventory. Br J Clin Psychol 1992;31:301-6.

20. Melzack R. The McGill Pain Questionnaire: Major properties and scoring methods. Pain 1975;1:277-99.

21. Nachemson A. Lumbar mechanics as revealed by lumbar intradiscal pressure measurements. In: Jayson MIV, ed. The Lumbar Spine and Back Pain. 4th ed. Edinburgh: Churchill Livingstone, 1992:157-71.

22. Nachemson AL. The lumbar spine: An orthopaedic challenge. Spine 1976; 1:59-71.

23. Nordin M. Back pain: Lessons from patient education. Patient Educ Counseling 1995;26:67-70.

24. Roberts LC. Control Issues and Low Back Pain. Unpublished thesis. England: University of Southampton, 1999.

25. Roland M, Dixon M. Randomized controlled trial of an educational booklet for patients presenting with back pain in general practice. J R Coll Gen Practit 1989;244-6.

26. Roland M, Morris R. A study of the natural history of back pain: Part 1 . Development of a reliable and sensitive measure of disability in low back pain. Spine 1983;8:141-4.

27. Ruta D, Garratt A, Wardlaw D, et al. Developing a valid and reliable measure of health outcome for patients with low back pain. Spine 1994;19: 1887-96.

28. Smith CE. Overview of patient education: Opportunities and challenges for the twenty-first century. Nurs Clin North Am 1989;24:583-7.

29. Wallston K, Wallston B, DeVellis R. Development of the multidimensional health locus of control scales. Health Educ Monogr 1978;6:160-70.

30. Wallston KA. Personal communication, 1994.

Address reprint requests to

Lisa Roberts, PhD, MCSP

School of Health Professions and Rehabilitation

Sciences

University of Southampton

Highfield, Southampton, Hants SO17 1BJ

United Kingdom 